\title{
Management of spinal cord injury after traumatic spine fractures in a middle-aged welder
}

\author{
Xiahong Li ${ }^{1}$, Xue Wang', Song Han ${ }^{2}$, Xiuquan $\mathrm{Shi}^{3}$ \\ From ${ }^{1}$ Master, ${ }^{3}$ Ph.D, Department of Epidemiology and Health Statistics, School of Public Health, Zunyi Medical University; ${ }^{2}$ Master, Department of \\ Orthopedics, Affiliated Hospital of Zunyi Medical University, Zunyi, Guizhou, China
}

\begin{abstract}
Traumatic spine fractures associated with injuries are uncommon but extremely severe that are known to cause significant long-term disability and socioeconomic burden. Therefore, the management after an injury is extremely crucial. We report a case of lumbar spine fracture complicated with cauda equina nerve injury. The patient had 2 years' history of hypertension and type 2 diabetes. American Spinal Injury Association (ASIA) impairment scale was Grade A. Surgeon performed posterior incision for reduction and decompression and spinal fusion with pedicle screw instrumentation at the L2-L3 level. Due to poor control of blood sugar and decreased resistance after the injury, post-operative incision healing was poor and infection occurred (Staphylococcus aureus). After debridement, drainage, and anti-infection treatment, the incision gradually healed. There was no neurological recovery on the saddle area and lower limbs even after 1 year.
\end{abstract}

Key words: Case report, Infection, Spinal cord injury, Traumatic spine fractures

$\mathrm{T}$ Traumatic spine fractures attributed to injuries are uncommon in nature and responsible for only $0.7 \%$ of total fractures in adult patients [1]. In Finland, the annual incidence of spine fractures that need medical treatment has been estimated to be $260-270 /$ million, whereas, in other countries, the numbers have ranged from 160 /million to $640 /$ million [2]. In the United States, the prevalence of spine fractures has been reported to be $5 \%$ among patients under 60 years old but increased to $18 \%$ among 80 years old persons [3]. Traumatic spine fractures hamper the quality of life of patients. It not only affects the normal activities of the patient but also cause serious obstacles to the patient's normal standing and walking. About $10 \%-20 \%$ of patients with spinal fractures sustain an undesirable outcome known as spinal cord injury (SCI) [2] which has a higher mortality rate than that of other traumas [4].

SCI occurs as a result of injury to the vertebral column, resulting in mechanical compression or deformation of the spinal cord, and secondary damage caused by ischemia, inflammation, and other mechanisms [5]. It is an important cause of morbidity that usually affects young people, causes a large amount of medical care expenditures, seriously threatens survival, and hampers the quality of life of the patient [6-8]. Therefore, the treatment of

\section{Access this article online}

Received - 20 February 2021

Initial Review - 09 March 2021

Accepted - 31 March 2021

DOI: $10.32677 /$ IJCR.2021.v07.i04.004 patients with SCI brings certain challenges to clinicians. It should not be ignored that the post-operative wound infection will be detrimental to the patient if it is not dealt with in time.

\section{CASE REPORT}

A 50-year-old male presented with complaints of back pain and restricted lower limb movements. The patient was referred to the emergency department after being injured by a heavy object from a height of $2 \mathrm{~m}$ for more than $5 \mathrm{~h}$.

On physical examination, the heart rate was 71 beats/min, blood pressure $160 / 100 \mathrm{mmHg}$, respiratory rate 20 times/min, and body temperature $36^{\circ} \mathrm{C}$. He had no motor power or sensation or physiological reflex on the saddle area and lower limbs (ASIA impairment Grade A) and severe tenderness on the L2-L3 area. There was an open external wound on his sacrococcygeal region burned by electric sparks about an area of a $7 \mathrm{~cm} \times 6 \mathrm{~cm}$ rectangle.

Laboratory investigations are presented in Table 1 . Radiological examination revealed a burst fracture of the L-3, severe anterior spondylolisthesis of the L-2, spinal canal stenosis, and fractures of the left transverse process in L-1 and L-4. Brain, abdomen, and pelvic Computed Tomography (CT) showed no obvious abnormalities in these tissues and organs. The cardiac examination was also normal. Chest $\mathrm{CT}$ revealed a small amount

Correspondence to: Xiuquan Shi, Department of Epidemiology and Health Statistics, School of Public Health, Zunyi Medical University, Zunyi, Guizhou, PR China. E-mail: xqshi@zmu.edu.cn

(C) 2021 Creative Commons Attribution-NonCommercial 4.0 International License (CC BY-NC-ND 4.0). 
Table 1: Indicator results of laboratory tests in the patient

\begin{tabular}{lc}
\hline Laboratory parameters & Values \\
\hline Fasting blood glucose, mmol/L & 20.95 \\
C-reactive protein (CRP), mg/L & 54.4 \\
Red blood cells, $\times 10^{12} / \mathrm{L}$ & 5.83 \\
White blood cells, $\times 10^{9} / \mathrm{L}$ & 11.51 \\
Neutrophils, \% & 0.82 \\
Absolute neutrophils, $\times 10^{9} / \mathrm{L}$ & 9.44 \\
Lymphocytes, $\%$ & 0.12 \\
Absolute lymphocytes, $\times 10^{9} / \mathrm{L}$ & 1.38 \\
Glycated hemoglobin, $\%$ & 10.7 \\
Interleukin-6, pg/ml & 38.75 \\
Procalcitonin, $\mathrm{ng} / \mathrm{ml}$ & 0.08 \\
\hline
\end{tabular}

of fibrosis in both lungs. No signs of organ (liver and kidney) dysfunction were unusual.

Given the imaging and clinical manifestations, he was diagnosed with multiple lumbar fractures complicated with cauda equina injury, closed thoracic trauma, and sacrococcygeal region burns. To prevent the spine fractures from getting worse, the surgeons made a decision to perform posterior incision for reduction and decompression and spinal fusion with pedicle screw instrumentation at the L2-L3 level (Fig. 1). Unfortunately, the patient developed an incision infection after surgery (Staphylococcus aureus infection); subsequently, the doctor performed debridement, drainage under general anesthesia on the infection site. During the surgery, the secretion was taken from the operation area, and bacterial culture and drug sensitivity results suggested that Staphylococcus aureus was sensitive to moxifloxacin.

Postoperatively, anti-infection treatment, antihypertensive, and hypoglycemic drugs were continuously administrated. Daily care dressing with burn ointment was offered on the sacrococcygeal region. Simultaneously, the deep veins in both lower limbs were monitored to avoid thrombosis. After reasonable adjustment of antibiotic treatment, normal blood sugar control, and nutritional support treatment, the patient's wound gradually healed. After two surgeries, therapy, and anti-infective treatment, the patient was discharged home after 48 days with advice on taking antihypertensive and hypoglycemic drugs on time and using protective gear during welding. However, there was no neurological recovery on the saddle area and lower limbs immediately or at 1 year follow-up after the operation.

\section{DISCUSSION}

Traumatic spine fractures are rare fractures, but it is a general consensus that these injuries can cause $\mathrm{SCI}$ and a higher mortality rate. SCI is a severe outcome, which not only leads to the impairment of sensory and motor functions below the injury level but also results in multiple organ dysfunctions, such as respiratory, circulatory, urinary, and digestive systems. Traumatic spine fractures often result in the loss of labor, usually requiring long-term rehabilitation treatment, occupying a large amount of medical and health resources, and

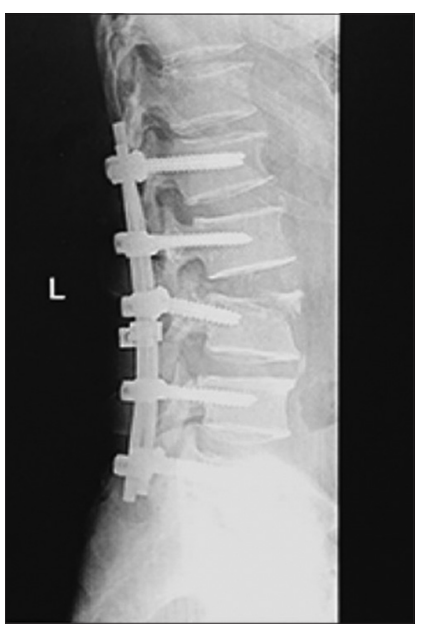

Figure 1: Lumbar spine computed tomography of the patient after surgery

expensive medical expenses. These all bring significant long-term disability to victims and heavy socioeconomic burdens to patients themselves, their families, and society [9].

Accidental fall is the predominant mechanism in spine fractures, with traffic accidents being the second most common etiology [9]. Traumatic spine fractures relative to a heavy object that smashes someone's spine are often overlooked by people, especially these workers with poor education and lack of any preventive facilities.

Many case reports are found in the previous literature stating the benefits of the surgery. Takahashi et al. reported a case of spinal cord injury in which duraplasty was performed. Neurologically, the sensory disturbance slightly improved 4 months after the injury [10]. Stauffer et al. found that there were no neurological benefits between surgical and non-surgical management of complete and incomplete spinal cord injuries [11]. Nevertheless, many studies on patients with acute spinal cord injury showed that rapid decompression and immobilization can lead to a good prognosis, and it was necessary to proceed with surgery immediately. Due to the neurological deficits, impaired alertness, or intricately systemic injuries that may be distracting, the treatment of patients with suspected spinal cord injuries is also challenging and needs to continue immobilization until imaging studies exclude unstable spinal injuries [5,12].

In addition, it is worth mentioning that though the lumber spine surgery was successfully conducted, the patient developed an incision infection. In general, post-operative infections are rare, because the operation is performed by an experienced doctor. Fortunately, the patient's wound gradually healed with the help of anti-infective treatment and the blood sugar was also controlled. Our patient's body resistance was poor due to the serious trauma. Moreover, he had type 2 diabetes for 2 years; high levels of blood sugar inhibit the phagocytosis of white blood cells, reducing the ability to prevent infection, as a high-sugar environment is "a good culture medium" for bacteria. Besides that, the patient's sacrococcygeal region (app. $6 \mathrm{~cm} \times 7 \mathrm{~cm}$ ) was burned by electric sparks, which suggested that the welder should wear insulated clothing and protective gloves under high-temperature operation. 


\section{CONCLUSION}

The case report emphasizes that traumatic fractures combined with spinal cord injury are serious, which cause significant longterm disability and socioeconomic burden. Timely and effective surgical treatment can prevent the patient's condition from getting worse. Close attention should be paid postoperatively as there are high chances for infection among such patients and if an infection is found, antibiotics should be used rationally for the respective pathogen.

\section{REFERENCES}

1. Charles M. Court-brown, ben Caesar. Epidemiology of adult fractures: A review. Injury 2006;37:691-7.

2. Niemi-Nikkola V, Saijets N, Ylipoussu H, Kinnunen P, Pesala J, Makela P, et al. Long-term posttraumatic survival of spinal fracture patients in Northern Finland. Spine (Phila Pa 1976) 2018;43:1657-63.

3. Cosman F, Krege JH, Looker AC, Schousboe JT, Fan B, Isfahani NS, et al. Spine fracture prevalence in a nationally representative sample of US women and men aged Finl Finln results from the National Health and Nutrition Examination Survey (NHANES) 2013-2014. Osteoporos Int 2017;28:1857-66.

4. Hasler RM, Exadaktylos AK, Bouamra O, Benneker LM, Clancy M, Sieber R, et al. Epidemiology and predictors of spinal injury in adult major trauma patients: European cohort study. Eur Spine J 2011;20:2174-80.

5. Lim DJ. Intraoperative finding and management of complete spinal cord transection after thoracolumbar traumatic fracture-dislocation: A case report. Medicine (Baltimore) 2021;100:e24096.

6. Devivo MJ. Epidemiology of traumatic spinal cord injury: Trends and future implications. Spinal Cord 2012;50:365-72.

7. Ahsan MK, Zaman N, Islam J. Management of spinal injuries in polytrauma patients: An experience of tertiary care hospital. Mymensingh Med J 2019;28:182-92.

8. Ahuja CS, Nori S, Tetreault L, Wilson J, Kwon B, Harrop J, et al. Traumatic spinal cord injury-repair and regeneration. Neurosurgery 2017;80:S9-S22.

9. Oliver M, Inaba K, Tang A, Branco BC, Barmparas G, Schnuriger B, et al. The changing epidemiology of spinal trauma: A 13-year review from a level I trauma centre. Injury 2012;43:1296-300.

10. Takahashi I, Iwasaki Y, Abumiya T, Imamura H, Houkin $\mathrm{K}$, Saitoh H, et al. Stab wounds of the spinal cord by a kitchen knife: Report of a case. No shinkei geka. Neurol Surg 1991;19:255-8.

11. Stauffer ES, Wood RW, Kelly EG. Gunshot wounds of the spine: the effects of laminectomy. J Bone Joint Surg Am 1979;61:389-92.

12. Hoffman JR, Mower WR, Wolfson AB, Todd KH, Zucker MI. Validity of a set of clinical criteria to rule out injury to the cervical spine in patients with blunt trauma. National emergency X-radiography utilization study group. $\mathrm{N}$ Engl J Med 2000;343:94-9.

Funding: This study was granted by National Natural Science Foundation of China (Grant No. 81560534, PI: Xiuquan Shi); Conflicts of Interest: The authors declare that they have no conflict of interest.

How to cite this article: Li X, Wang X, Han S, Shi X. Management of spinal cord injury after traumatic spine fractures in a middle-aged welder. Indian J Case Reports. 2021;7(4):137-139. 